\title{
Connexin and pannexin (hemi)channels in the liver
}

\section{Michaël Maes ${ }^{1}$, Elke Decrock ${ }^{2}$, Bruno Cogliati ${ }^{3}$, André G. Oliveira $^{4}$, Pedro E. Marques ${ }^{4}$, Maria L. Z. Dagli ${ }^{3}$, Gustavo B. Menezes ${ }^{4}$, Gregory Mennecier ${ }^{3}$, Luc Leybaert ${ }^{2}$, Tamara Vanhaecke ${ }^{1}$, Vera Rogiers ${ }^{1}$ and Mathieu Vinken ${ }^{1}$}

\author{
1 Department of Toxicology, Center for Pharmaceutical Research, Vrije Universiteit Brussel, Brussels, Belgium \\ 2 Physiology Group, Department of Basic Medical Sciences, Ghent University, Ghent, Belgium \\ ${ }^{3}$ Department of Pathology, School of Veterinary Medicine and Animal Science, University of Sao Paulo, Sao Paulo, Brazil \\ ${ }^{4}$ Department of Morphology, Institute of Biological Sciences, Universidade Federal de Minas Gerais, Belo Horizonte, Brazil
}

Edited by:

Mauricio A. Retamal, Universidad del Desarrollo, Chile

Reviewed by:

Steffany A. L. Bennett, University of Ottawa, Canada

Eric C. Beyer, University of Chicago, USA

\section{*Correspondence:}

Michaël Maes, Department of

Toxicology, Faculty of Medicine and

Pharmacy, Center for

Pharmaceutical Research, Vrije

Universiteit Brussel, Laarbeeklaan

103, B-1090 Brussels, Belgium

e-mail:michael.mc.maes@vub.ac.be
The liver was among the first organs in which connexin proteins have been identified. Hepatocytes harbor connexin32 and connexin26, while non-parenchymal liver cells typically express connexin43. Connexins give rise to hemichannels, which dock with counterparts on adjacent cells to form gap junctions. Both hemichannels and gap junctions provide pathways for communication, via paracrine signaling or direct intercellular coupling, respectively. Over the years, hepatocellular gap junctions have been shown to regulate a number of liver-specific functions and to drive liver cell growth. In the last few years, it has become clear that connexin hemichannels are involved in liver cell death, particularly in hepatocyte apoptosis. This also holds true for hemichannels composed of pannexin1, a connexin-like protein recently identified in the liver. Moreover, pannexin1 hemichannels are key players in the regulation of hepatic inflammatory processes. The current paper provides a concise overview of the features of connexins, pannexins and their channels in the liver.

Keywords: connexin, pannexin, hemichannel, gap junction, hepatocyte, cell death, inflammation

\section{INTRODUCTION}

The liver is a unique organ endowed with a plethora of specialized functions and a strong regenerative capacity. The establishment of communicative networks between the different liver cell types is therefore indispensable. Non-parenchymal liver cells preferentially have paracrine or juxtacrine contacts amongst themselves and with other hepatic cell types (Kmieć, 2001). Hepatocytes, the most prominent liver cell population, directly communicate with each other through gap junctions. The latter are formed by headto-head docking of 2 hemichannels of neighboring cells, which in turn are composed of 6 connexin $(\mathrm{Cx})$ proteins (Figure 1) (Vinken et al., 2006, 2008, 2009, 2010a,b, 2011; Decrock et al., 2009, 2011). Historically, these hemichannels have been considered as merely structural precursors of gap junctions. In the last decade, an accumulating body of evidence points to independent roles for hemichannels in cellular signaling by connecting the intracellular compartment with the extracellular environment (Vinken et al., 2006, 2010b; Decrock et al., 2009, 2011). More recently, a novel class of connexin-like proteins, the pannexin (Panx) proteins, has been identified. They assemble in a hemichannel configuration and are also named "single membrane channels" instead of hemichannels, as they do not appear to form gap junctions (D'Hondt et al., 2011; Bennett et al., 2012; Dahl and Keane, 2012; Wang et al., 2013a). In contrast to gap junctions, connexin and pannexin hemichannels seem to be mainly involved in pathological processes, including cell death

Abbreviations: ATP, adenosine $5^{\prime}$ triphosphate; $\mathrm{Cx}$, connexin; GJIC, gap junctional intercellular communication; IP3, inositol triphosphate; $\mathrm{P}_{2} \mathrm{X}_{7} \mathrm{R}, \mathrm{P}_{2} \mathrm{X}_{7}$ receptors; Panx, pannexin; UTP, uridine $5^{\prime}$ triphosphate. and inflammation (Decrock et al., 2009; D'Hondt et al., 2009; Chekeni et al., 2010; Ganz et al., 2011; Bennett et al., 2012). These emerging roles for connexin and pannexin hemichannels are discussed in the present paper with focus on their relevance to liver (dys)functionality. Furthermore, an updated overview of the currently available knowledge regarding hepatic connexin and pannexin expression as well as liver gap junctions is provided.

\section{CONNEXINS AND PANNEXINS IN THE LIVER}

At present, more than 20 connexin proteins have been identified in human beings and rodents. They all share a similar structure consisting of 4 membrane-spanning domains, 2 extracellular loops, a cytoplasmic loop, and cytosolic N-terminal and C-terminal regions (Figure 1). The different connexin family members are typically named after their molecular weight expressed in kilodaltons (Decrock et al., 2009; Vinken et al., 2009). Hepatocytes express Cx32 and to a lesser extent Cx26, which represents about 90 and 5\%, respectively, of the total connexin amount in rat and human livers. In contrast, most non-parenchymal liver cells, including stellate cells and Kupffer cells, mainly harbor $\mathrm{Cx} 43$, while liver vascular cells predominantly express Cx37 and Cx40 (Figure 2) (Kumar and Gilula, 1986; Paul, 1986; Nicholson et al., 1987; Zhang and Nicholson, 1989; Chaytor et al., 2001; Bode et al., 2002; Fischer et al., 2005; Shiojiri et al., 2006). A typical hallmark of the liver includes zonation, which is also manifested at the connexin level. Indeed, Cx32 is uniformly distributed throughout the liver, whereas $\mathrm{Cx} 26$ is preferentially expressed in the periportal acinar area (Berthoud et al., 1992; Kojima et al., 1995; Iwai et al., 2000). Liver connexin 

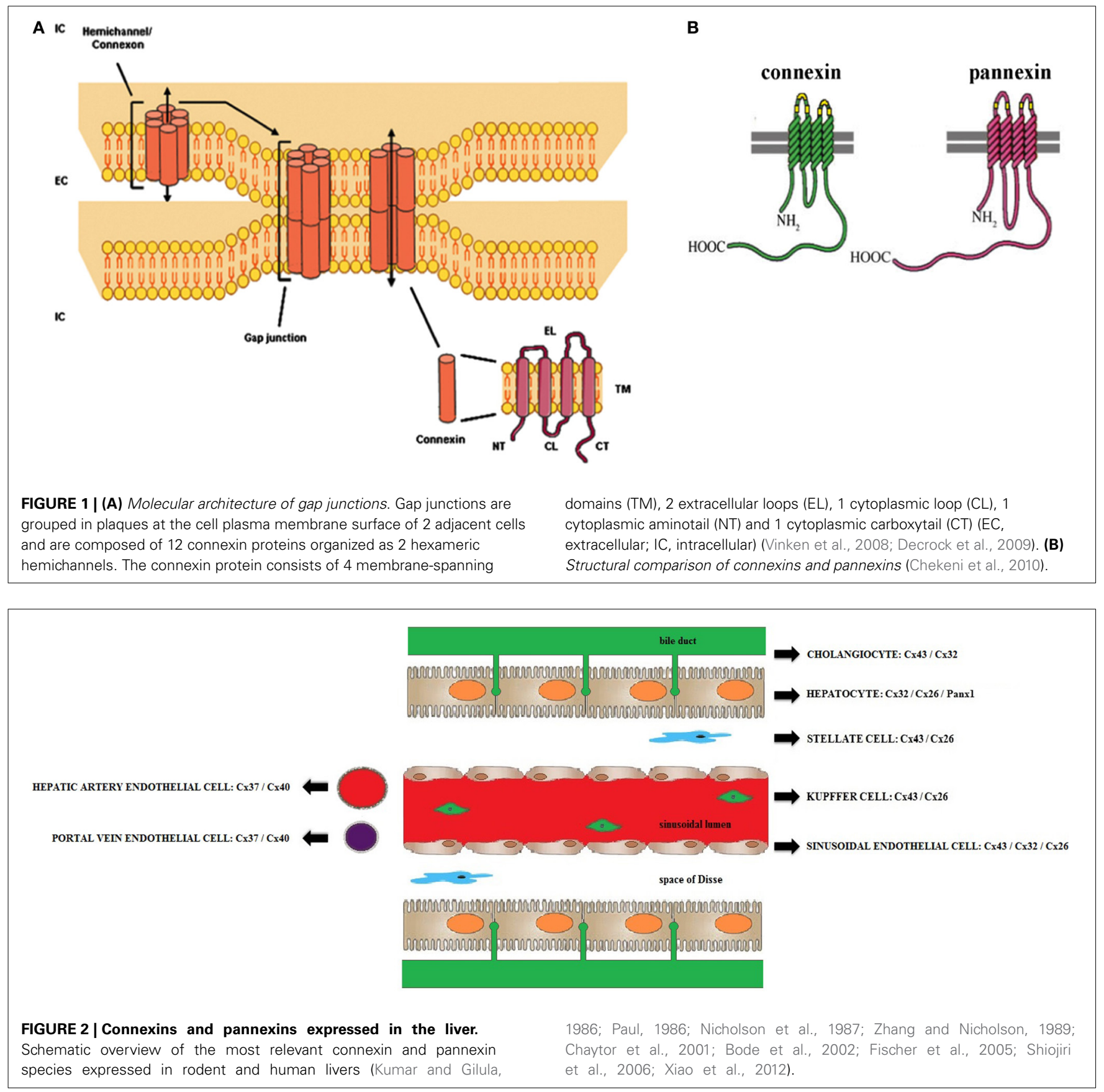

expression patterns undergo drastic changes upon both differentiation (i.e., liver organogenesis) and dedifferentiation (i.e., liver disease) (Vinken, 2012; Vinken et al., 2008, 2012a). Specifically, early hepatic progenitor cells switch from $\mathrm{Cx} 43$ to $\mathrm{Cx} 26$, but especially to $\mathrm{Cx} 32$ during differentiation into hepatocytes (Zhang and Thorgeirsson, 1994; Neveu et al., 1995; Naves et al., 2001; Paku et al., 2004). An inverse process is observed when chronic liver disease, such as liver fibrosis and cirrhosis, progressively turns into liver cancer (Vinken, 2012). Moreover, connexin expression and subcellular localization are significantly altered during liver cell growth (Traub et al., 1983; Kren et al., 1993; Temme et al.,
2000). Proliferation is a rare event in the adult liver, but upon partial hepatectomy, the remaining liver lobes start to grow and the original size becomes restored within a week (Taub, 2004). Cx32 expression was found to increase during early hepatocyte cell cycling, followed by a sharp decline (Traub et al., 1983; Dermietzel et al., 1987; Sugiyama and Ohta, 1990; Miyashita et al., 1991; Kren et al., 1993; Temme et al., 2000; Kojima et al., 2003). Less consistent changes have been reported for Cx26 (Kren et al., 1993; Temme et al., 2000). Furthermore, Cx37 and Cx40 are clearly upregulated, while $\mathrm{Cx} 43$ tends to stay unaffected during liver regeneration (Kren et al., 1993). 
Only 3 pannexin proteins have yet been characterized. They show structural similarity with connexin proteins, though pannexins typically have longer C-terminal regions and extracellular loops (D'Hondt et al., 2011; Wang et al., 2013a). Unlike connexins, very little is known about the occurrence of pannexins in the liver, although a number of studies have demonstrated the presence of Panx1 (Bruzzone et al., 2003; Csak et al., 2011; Ganz et al., 2011). In a more recent study, Panx1 mRNA was detected in cultured rat primary hepatocytes as well as in rat and human cancerous hepatocytes (Xiao et al., 2012). A single study also showed expression of Panx 2 in the lateral plasma membrane fraction of primary rat hepatocytes (Li et al., 2008).

\section{GAP JUNCTIONS IN THE LIVER}

In the liver, the vast majority of gap junctions are formed between hepatocytes. They occupy as much as $3 \%$ of the hepatocellular membrane surface and form gap junctional plaques ranging from 0.2 to $1 \mu \mathrm{m}$ in diameter and containing from 10 to more than 10,000 gap junction channels. Hepatocellular gap junctions in the pericentral acinar area mainly consist of homomeric hemichannels (i.e., containing $\mathrm{Cx} 32$ ), whereas their periportal counterparts can also be built up by heteromeric hemichannels (i.e., composed of both Cx26 and Cx32) (Vinken et al., 2008). Cx32 in the liver interacts with several other junctional proteins, such as occludin and claudin1 (Kojima et al., 2001), but also with mitochondrial proteins, including sideroflexin1 (Fowler et al., 2013). Gap junctions provide a generic pathway for communication between adjacent cells, called gap junctional intercellular communication (GJIC). GJIC includes the passive diffusion of small and hydrophilic molecules, such as cyclic adenosine monophosphate, adenosine 5' triphosphate (ATP), inositol triphosphate (IP3) and ions (Alexander and Goldberg, 2003; Dbouk et al., 2009; Decrock et al., 2009; Vinken et al., 2011). Homotypic Cx26 gap junctions favor cation transfer, whereas homotypic Cx32 gap junctions promote anion passage (Bukauskas et al., 1995). Likewise, ATP passes significantly better through gap junctions formed by $\mathrm{Cx} 43$ compared to $\mathrm{Cx} 32$-based channels (Goldberg et al., 2002).

Hepatocellular gap junctions are indispensable for maintaining the metabolic competence of the liver. In particular, Cx32-based GJIC underlies a number of liver-specific functions, including glycogenolysis (Stumpel et al., 1998), albumin secretion (Yang et al., 2003), bile secretion (Temme et al., 2001), ammonia detoxification (Yang et al., 2003) and xenobiotic biotransformation (Neveu et al., 1994; Shoda et al., 1999, 2000). Curiously, genetic ablation of $\mathrm{Cx} 26$ and $\mathrm{Cx} 32$ in mice does not drastically alter basal liver functionality (Ott et al., 2006). In line with this finding, Cx26 gene mutations in humans have been associated with skin diseases and deafness, but not with abnormalities in the liver (Lee and White, 2009), yet these patients display a gain of Cx26 hemichannel function (Mhaske et al., 2013). Similarly, human Cx32 gene mutations typically lead to neurological disorders, while leaving the liver largely unaffected (Abrams et al., 2000). However, Cx32-deficient mice, unlike their Cx26-lacking counterparts (Marx-Stoelting et al., 2008), have been found more susceptible to spontaneously occurring and chemically induced hepatocarcinogenesis (Temme et al., 1997).
The biochemical identity of the messengers that travel through hepatocyte gap junctions and that affect liver functionality remains largely elusive, though an exception exists for glycogenolysis. Breakdown of glycogen to glucose is triggered by hormonal and neuronal stimuli and predominantly occurs at the periportal acinar pole. Pericentral hepatocytes also show glycogenolytic activity, albeit to a lesser extent (Stumpel et al., 1998; Saez et al., 2003). Cx32-based gap junctions therefore drive the propagation of the glycogenolytic response from the periportal to the pericentral area. In fact, they facilitate the intercellular exchange of IP3, which activates calcium release from endoplasmic reticulum stores, in turn evoking calcium waves throughout the acinar tract (Clair et al., 2001; Saez et al., 2003; Gaspers and Thomas, 2005). Indeed, Cx32 knock-out mice display lowered blood glucose levels upon glycogenolytic stimulation (Nelles et al., 1996; Stumpel et al., 1998). Similarly, the spread of calcium waves through Cx43-based gap junctions controls ductular secretion from cholangiocytes and thus bile formation (Nathanson et al., 1999; Bode et al., 2002).

GJIC is clearly involved in liver cell growth. However, the exact role and overall relevance of gap junctions in hepatocyte cell cycling is matter of debate. In the regenerating liver of rats treated with an inhibitor of the mitogen-activated protein kinase pathway, the reduction of $\mathrm{Cx} 32$ production is counteracted, with no effects on hepatocyte proliferative activity (Kojima et al., 2003). This indicates that downregulation of GJIC may occur independently of hepatocyte proliferation. In the regenerating liver of Cx32 knock-out mice, hepatocellular proliferative activity is not affected, but the extent of synchronous initiation and termination of DNA synthesis is decreased (Kojima et al., 1997; Temme et al., 2000). Based on this observation, reduction of GJIC does not provide a direct signal for hepatocytes to divide, but rather permits cell cycle progression upon mitogenic stimulation. On the other hand, a plethora of studies have shown determinate functions for gap junctions in liver cell proliferation control, rather than merely an assisting role in growth progression (Koffler et al., 2000; Ruch, 2000; Yano et al., 2001). It should be stressed, however, that such studies typically rely on genetic ablation of connexin expression, thus impeding discrimination between GJIC and connexin hemichannel communication.

\section{CONNEXIN AND PANNEXIN HEMICHANNELS IN THE LIVER}

Although still surrounded by a lot of controversy, it is now accepted that connexin hemichannels autonomously establish a pathway for cellular signaling between the cytosol of individual cells and their extracellular environment (Decrock et al., 2009; Chandrasekhar and Bera, 2012; Kar et al., 2012). The messengers that diffuse through connexin hemichannels are very similar to those that can permeate gap junctions and typically include ATP, glutamate and glutathione. However, in contrast to gap junctions, connexin hemichannels have a low probability to be open. They can be opened by a number of stimuli that are of pathological origin, such as changes in extracellular or intracellular calcium concentration, oxidative stress, induced metabolic inhibition, ischemia/reperfusion insults and inflammatory conditions. Hence, connexin hemichannels are frequently referred to as pathological pores (Decrock et al., 2009; Chandrasekhar 
and Bera, 2012; Kar et al., 2012). This has been well exemplified in the context of cell death. Although a limited set of reports described cytoprotective functions for connexin hemichannels (Plotkin et al., 2002; Okuda et al., 2013), most scientific evidence available points to pro-active roles for connexin hemichannels in the cell death process, involving the formation of a toxic pore or contributing to a paracrine cell death pathway (Kalvelyte et al., 2003; Takeuchi et al., 2006; Ramachandran et al., 2007; Decrock et al., 2009). Connexin hemichannels not only occur at the plasma membrane surface, but also reside at other subcellular locations, such as the mitochondria, where they have been linked to cell survival (Goubaeva et al., 2007; Lu et al., 2010; Azarashvili et al., 2011; Trudeau et al., 2012; Fowler et al., 2013). In this context, Cx43 translocates to the mitochondria where it interacts with Bax to initiate the mitochondrial apoptotic pathway in pancreatic cancer cells (Sun et al., 2012). Furthermore, mitochondrial Cx43 plays a role in myocardial ischemia-reperfusion injury by interfering with reactive oxygen species signaling (Ruiz-Meana et al., 2008) and facilitates ATP production (Boengler et al., 2012). More recently, mitochondrial Cx43-based hemichannels were found to assist in mitochondrial potassium uptake (Boengler et al., 2013).

Our group was the first to show the functional presence of connexin hemichannels in hepatocytes. Upon induction of Fasmediated apoptosis in cultures of primary hepatocytes, GJIC rapidly declines, which is associated with a decay of the gap junctional Cx32 protein pool. At the same time, levels of newly synthesized Cx32 protein increase and gather in a hemichannel configuration. This becomes particularly evident toward the end stages of the cell death process (Vinken et al., 2010c). Subsequent experiments showed that $\mathrm{Cx} 32$-based hemichannels facilitate the apoptotic-to-necrotic transition in hepatocytes. Primary hepatocytes in culture are known to progressively lose their differentiated status, whereby $\mathrm{Cx} 43$ becomes de novo produced. Work with specific channel inhibitors demonstrated that $\mathrm{Cx} 43$ signaling, also involving hemichannels, underlies the onset of spontaneous apoptosis, which accompanies the dedifferentiation process in cultures of primary hepatocytes (Vinken et al., 2012b). In a more recent study, $\mathrm{Cx} 43$ production in cultured hepatocytes was epigenetically silenced followed by global protein and metabolite profiling. Among the proteins altered were several mitochondrial proteins. These data thus could further substantiate the existence of a mitochondrial connexin pool, and can be reconciled with a role for Cx43 signaling in spontaneously occurring apoptosis in primary hepatocyte cultures (Vinken et al., 2013).

Pannexin hemichannels have also been identified as mediators of apoptotic processes (Chekeni et al., 2010; Qu et al., 2011; Sandilos et al., 2012). Pannexin hemichannels can be opened by various pathological stimuli such as oxygen glucose deprivation, metabolic inhibition and S-nitrosylation (Thompson et al., 2006; Zhang et al., 2008). Similar to connexins (Yin et al., 2001; Theiss et al., 2007), Panx1 is an established target for caspases, which results in the formation of a constitutively open channel and the release of the so-called "find-me" signals, such as ATP and uridine $5^{\prime}$ triphosphate (UTP), at the earliest stages of cell death in order to recruit phagocytes (Chekeni et al., 2010; Sandilos et al., 2012). Both nucleotides act as "damage-associated molecular patterns," which are released during immunogenic cell death and serve as a signal to initiate and amplify cell death as well as to induce inflammation (Elliott et al., 2009; Chekeni et al., 2010). In fact, Panx1 plays a major role in the regulation of inflammatory processes and thus in innate immunity. Panx1 is instrumental for activating the inflammasome, a multiprotein complex involved in innate immunity and caspase 1 activation, and subsequent processing and release of the pro-inflammatory cytokines interleukin 1 beta and interleukin 18. Activation of the inflammasome has been seen in lipopolysaccharide-stimulated macrophages (Pelegrin and Surprenant, 2006, 2007) as well as in astrocytes and neurons (Silverman et al., 2009). Further investigation demonstrated that Panx1 hemichannel opening, induced by ATP stimulation of $\mathrm{P}_{2} \mathrm{X}_{7}$ receptors $\left(\mathrm{P}_{2} \mathrm{X}_{7} \mathrm{R}\right)$, facilitates the entry of bacterial inflammatory signals into the cytosol (Kanneganti et al., 2007). Panxl is known to co-localize with the $\mathrm{P}_{2} \mathrm{X}_{7} \mathrm{R}$ and to form a "death receptor" complex (Locovei et al., 2007). Here, prolonged stimulation of the $\mathrm{P}_{2} \mathrm{X}_{7} \mathrm{R}$ results in the opening of a non-selective pore that may correspond to the Panxl hemichannel. Extracellular ATP acts on the $\mathrm{P}_{2} \mathrm{X}_{7} \mathrm{R}$, leading to Panx1 hemichannel opening (Pelegrin and Surprenant, 2006, 2007; Locovei et al., 2007; Iglesias et al., 2008). This mechanism may also apply for connexins, since $\mathrm{Cx} 43$ and $\mathrm{P}_{2} \mathrm{X}_{7} \mathrm{R}$ were seen to co-localize and co-immunoprecipitate in mouse macrophages and J774 cells (Fortes et al., 2004). However, a more recent study based on the use of Panx $1^{-/-}$mice and $\mathrm{P}_{2} \mathrm{X}_{7} \mathrm{R}^{-/-}$mice demonstrated that Panx 1 and the $\mathrm{P}_{2} \mathrm{X}_{7} \mathrm{R}$ function in distinct signaling pathways. Whereas only the $\mathrm{P}_{2} \mathrm{X}_{7} \mathrm{R}$ was necessary for inflammatory responses in lipopolysaccharideprimed macrophages, Panx1 was dispensable in the migrating phagocyte but was essential for the release of the "find me" signals from apoptotic cells to recruit macrophages (Qu et al., 2011).

Treatment of mice with lipopolysaccharide, results in elevated levels of Panx1 in the liver. Also, an increased production of active interleukin 1 beta and interleukin 18 is observed under these circumstances (Ganz et al., 2011). In addition to driving the inflammasome, Panxl contributes to pathophysiological ATP release in lipoapoptosis induced by saturated free fatty acids, a key morphologic and pathological feature of human non-alcoholic steatohepatitis. Using a rat liver cell line, it has been shown that saturated free fatty acids increase extracellular ATP concentrations. Extracellular ATP release as well as cytosolic uptake of an indicator dye were partly inhibited by suppressing Panx1 expression (Xiao et al., 2012). Thus, Panx1-based hemichannels may play an important role in hepatic inflammation by mediating an increase in extracellular ATP levels in lipotoxic liver injury.

\section{CONCLUSIONS AND PERSPECTIVES}

Although still being in its infancy, it has become clear in the last few years that connexin and pannexin hemichannels fulfill critical functions in the regulation of cell death and inflammation. Only a handful of published reports have addressed these features in the liver and all of those rely on the use of in vitro settings (Decrock et al., 2009; D'Hondt et al., 2009; Chekeni et al., 2010; Ganz et al., 2011). Although some physiological roles have been attributed to hemichannels (Penuela et al., 2013), this remains to be demonstrated in the liver. It will be challenging in the upcoming years to evaluate the in vivo relevance of hepatic connexin and pannexin hemichannels. Several liver diseases, such as hepatitis, fibrosis and 
cholestasis, are associated not only with the onset of cell death and inflammation, but also with modifications in connexin expression patterns and activity (Vinken, 2012). In fact, as discussed in the current paper, it is conceivable to assume that connexin, but especially, pannexin hemichannels drive the process of hepatocyte cell demise by releasing "find me" signals to initiate their clearance (Chekeni et al., 2010). Furthermore, recent data suggest the critical involvement of Panx1 hemichannels in liver inflammation (Ganz et al., 2011; Xiao et al., 2012). The knowledge that will be gained in this respect in the upcoming years could open new perspectives for clinical therapy. Thus far, 2 studies have pinpointed the potential of interfering with hepatic connexin signaling in the clinical management of acute (Patel et al., 2012) and acute-onchronic liver failure (Balasubramaniyan et al., 2013). However, these studies did not distinguish between GJIC and connexin hemichannel communication. Given the opposite roles of gap junctions and connexin hemichannels in the (dys)regulation of the homeostatic balance in the liver, such discrimination is key for a targeted and efficient clinical outcome. Specific and in vivoapplicable connexin hemichannel inhibitors have become available only very recently (Iyyathurai et al., 2013; Wang et al., 2013b). In this respect, a peptide called Gap19 was found to specifically block Cx43-based hemichannel signaling and to reduce cell death in a mouse model of cardiac ischemia/reperfusion insult (Wang et al., 2013c). Future efforts should be focused on the further development of such tools as well as on the testing of their clinical applicability, stressing the importance of the field of hepatology.

\section{ACKNOWLEDGMENTS}

This work was financially supported by the grants of the Agency for Innovation by Science and Technology in Flanders (IWT), the University Hospital of the Vrije Universiteit Brussel-Belgium (Willy Gepts Fonds UZ-VUB), the Fund for Scientific ResearchFlanders (FWO grants G009514N and G010214N), the European Research Council (ERC Starting Grant 335476), the University of Sao Paulo-Brazil (USP) and the Foundation for Research Support of the State of Sao Paulo (FAPESP SPEC grant 2013/50420-6).

\section{REFERENCES}

Abrams, C. K., Oh, S., Ri, Y., and Bargiello, T. A. (2000). Mutations in connexin 32: the molecular and biophysical bases for the X-linked form of CharcotMarie-Tooth disease. Brain Res. Brain Res. Rev. 32, 203-214. doi: 10.1016/S01650173(99)00082-X

Alexander, D. B., and Goldberg, G. S. (2003). Transfer of biologically important molecules between cells through gap junction channels. Cur. Med. Chem. 10, 2045-2058. doi: 10.2174/0929867033456927

Azarashvili, T., Baburina, Y., Grachev, D., Krestinina, O., Evtodienko, Y., Stricker, R., et al. (2011). Calcium-induced permeability transition in rat brain mitochondria is promoted by carbenoxolone through targeting connexin43. Am. J. Physiol. Cell Physiol. 300, C707-C720. doi: 10.1152/ajpcell.00061.2010

Balasubramaniyan, V., Dhar, D. K., Warner, A. E., Lil, W.-Y. V., Amiri, A. F., Bright, B., et al. (2013). Importance of Connexin-43 based gap junction in cirrhosis and acute-on-chronic liver failure. J. Hepatol. 58, 1194-1200. doi: 10.1016/j.jhep.2013.01.023

Bennett, M. V. L., Garre, J. M., Orellana, J. A., Bukauskas, F. F., Nedergaard, M., Giaume, C., et al. (2012). Connexin and pannexin hemichannels in inflammatory responses of glia and neurons. Brain Res. 1487, 3-15. doi: 10.1016/j.brainres.2012.08.042

Berthoud, V. M., Iwanij, V., Garcia, A. M., and Saez, J. C. (1992). Connexins and glucagon receptors during development of rat hepatic acinus. Am. J. Physiol. 263, G650-G658.
Bode, H. P., Wang, L. F., Cassio, D., Leite, M. F., St-Pierre, M. V., Hirata, K., et al. (2002). Expression and regulation of gap junctions in rat cholangiocytes. Hepatology 36, 631-640. doi: 10.1053/jhep.2002.35274

Boengler, K., Ruiz-Meana, M., Gent, S., Ungefug, E., Soetkamp, D., Miro-Casas, E., et al. (2012). Mitochondrial connexin 43 impacts on respiratory complex I activity and mitochondrial oxygen consumption. J. Cell. Mol. Med. 16, 1649-1655. doi: 10.1111/j.1582-4934.2011.01516.x

Boengler, K., Ungefug, E., Heusch, G., Leybaert, L., and Schulz, R. (2013). Connexin 43 impacts on mitochondrial potassium uptake. Front. Pharmacol. 4:73. doi: 10.3389/fphar.2013.00073

Bruzzone, R., Hormuzdi, S. G., Barbe, M. T., Herb, A., and Monyer, H. (2003). Pannexins, a family of gap junction proteins expressed in brain. Proc. Natl. Acad. Sci. U.S.A. 100, 13644-13649. doi: 10.1073/pnas.2233464100

Bukauskas, F. F., Elfgang, C., Willecke, K., and Weingart, R. (1995). Heterotypic gap junction channels (connexin26 or connexin32) violate the paradigm of unitary conductance. Pflugers Arch. 429, 870-872. doi: 10.1007/BF00374812

Chandrasekhar, A., and Bera, A. K. (2012). Hemichannels: permeants and their effect on development, physiology and death. Cell Biochem. Funct. 30, 89-100. doi: 10.1002/cbf.2794

Chaytor, A. T., Martin, P. E. M., Edwards, D. H., and Griffith, T. M. (2001). Gap junctional communication underpins EDHF-type relaxations evoked by ACh in the rat hepatic artery. Am. J. Physiol. Heart Circ. Physiol. 280, H2441-H2450.

Chekeni, F. B., Elliott, M. R., Sandilos, J. K., Walk, S. F., Kinchen, J. M., Lazarowski, E. R., et al. (2010). Pannexin 1 channels mediate find-me signal release and membrane permeability during apoptosis. Nature 467, 863-867. doi: 10.1038/nature09413

Clair, C., Chalumeau, C., Tordjmann, T., Poggioli, J., Erneux, C., Dupont, G., et al. (2001). Investigation of the roles of $\mathrm{Ca} 2+$ and $\operatorname{InsP}(3)$ diffusion in the coordination of $\mathrm{Ca} 2+$ signals between connected hepatocytes. J. Cell Sci. 114, 1999-2007.

Csak, T., Ganz, M., Pespisa, J., Kodys, K., Dolganiuc, A., and Szabo, G. (2011). Fatty acid and endotoxin activate inflammasomes in mouse hepatocytes that release danger signals to stimulate immune cells. Hepatology 54, 133-144. doi: 10.1002/hep. 24341

D'Hondt, C., Ponsaerts, R., de Smedt, H., Bultynck, G., and Himpens, B. (2009). Pannexins, distant relatives of the connexin family with specific cellular functions? Bioessays 31, 953-974. doi: 10.1002/bies.200800236

D'Hondt, C., Ponsaerts, R., de Smedt, H., Vinken, M., de Vuyst, E., de Bock, M., et al. (2011). Pannexin channels in ATP release and beyond: an unexpected rendezvous at the endoplasmic reticulum. Cell Signal. 23, 305-316. doi: 10.1016/j.cellsig.2010.07.018

Dahl, G., and Keane, R. W. (2012). Pannexin: From discovery to bedside in 11 +/4 years? Brain Res. 1487, 150-159. doi: 10.1016/j.brainres.2012.04.058

Dbouk, H. A., Mroue, R. M., El-Sabban, M. E., and Talhouk, R. S. (2009). Connexins: a myriad of functions extending beyond assembly of gap junction channels. Cell Commun. Signal. 7, 4. doi: 10.1186/1478-811X-7-4

Decrock, E., Vinken, M., Bol, M., D’Herde, K., Rogiers, V., Vandenabeele, P., et al. (2011). Calcium and connexin-based intercellular communication, a deadly catch? Cell Calcium 50, 310-321. doi: 10.1016/j.ceca.2011.05.007

Decrock, E., Vinken, M., de Vuyst, E., Krysko, D. V., D’Herde, K., Vanhaecke, T., et al. (2009). Connexin-related signaling in cell death: to live or let die? Cell Death Differ. 16, 524-536. doi: 10.1038/cdd.2008.196

Dermietzel, R., Yancey, S. B., Traub, O., Willecke, K., and Revel, J. P. (1987). Major loss of the $28-\mathrm{kD}$ protein of gap junction in proliferating hepatocytes. J. Cell Biol. 105, 1925-1934. doi: 10.1083/jcb.105.4.1925

Elliott, M. R., Chekeni, F. B., Trampont, P. C., Lazarowski, E. R., Kadl, A., Walk, S. F., et al. (2009). Nucleotides released by apoptotic cells act as a find-me signal to promote phagocytic clearance. Nature 461, 282-286. doi: 10.1038/nature08296

Fischer, R., Reinehr, R., Lu, T. P., Schonicke, A., Warskulat, U., Dienes, H. P., et al. (2005). Intercellular communication via gap junctions in activated rat hepatic stellate cells. Gastroenterology 128, 433-448. doi: 10.1053/j.gastro.2004. 11.065

Fortes, F. S. A., Pecora, I. L., Persechini, P. M., Hurtado, S., Costa, V., Coutinho-Silva, R., et al. (2004). Modulation of intercellular communication in macrophages: possible interactions between GAP junctions and $\mathrm{P} 2$ receptors. J. Cell Sci. 117, 4717-4726. doi: 10.1242/jcs.01345

Fowler, S. L., Akins, M., Zhou, H., Figeys, D., and Bennett, S. A. (2013). The liver connexin 32 interactome is a novel plasma membrane-mitochondrial signaling nexus. J. Proteome Res. 12, 2597-2610. doi: 10.1021/pr301166p 
Ganz, M., Csak, T., Nath, B., and Szabo, G. (2011). Lipopolysaccharide induces and activates the Nalp3 inflammasome in the liver. World J. Gastroenterol. 17, 4772-4778. doi: 10.3748/wjg.v17.i43.4772

Gaspers, L. D., and Thomas, A. P. (2005). Calcium signaling in liver. Cell Calcium 38, 329-342. doi: 10.1016/j.ceca.2005.06.009

Goldberg, G. S., Moreno, A. P., and Lampe, P. D. (2002). Gap junctions between cells expressing connexin 43 or 32 show inverse permselectivity to adenosine and ATP. J. Biol. Chem. 277, 36725-36730. doi: 10.1074/jbc.M109797200

Goubaeva, F., Mikami, M., Giardina, S., Ding, B., Abe, J., and Yang, J. (2007). Cardiac mitochondrial connexin 43 regulates apoptosis. Biochem. Biophys. Res. Commun. 352, 97-103. doi: 10.1016/j.bbrc.2006.10.177

Iglesias, R., Locovei, S., Roque, A., Alberto, A. P., Dahl, G., Spray, D. C., et al. (2008). P2X(7) receptor-Pannexin1 complex: pharmacology and signaling. Am. J. Physiol. Cell Physiol. 295, C752-C760. doi: 10.1152/ajpcell.00228.2008

Iwai, M., Harada, Y., Muramatsu, A., Tanaka, S., Mori, T., Okanoue, T., et al. (2000). Development of gap junctional channels and intercellular communication in rat liver during ontogenesis. J. Hepatol. 32, 11-18. doi: 10.1016/S01688278(00)80184-1

Iyyathurai, J., D’Hondt, C., Wang, N., De Bock, M., Himpens, B., Retamal, M. A., et al. (2013). Peptides and peptide-derived molecules targeting the intracellular domains of Cx43: Gap junctions versus hemichannels. Neuropharmacology 75, 491-505. doi: 10.1016/j.neuropharm.2013.04.050

Kalvelyte, A., Imbrasaite, A., Bukauskiene, A., Verselis, V. K., and Bukauskas, F. F. (2003). Connexins and apoptotic transformation. Biochem. Pharmacol. 66, 1661-1672. doi: 10.1016/S0006-2952(03)00540-9

Kanneganti, T. D., Lamkanfi, M., Kim, Y. G., Chen, G., Park, J. H., Franchi, L., et al. (2007). Pannexin-1-mediated recognition of bacterial molecules activates the cryopyrin inflammasome independent of Toll-like receptor signaling. Immunity 26, 433-443. doi:10.1016/j.immuni.2007.03.008

Kar, R., Batra, N., Riquelme, M. A., and Jiang, J. X. (2012). Biological role of connexin intercellular channels and hemichannels. Arch. Biochem. Biophys. 524, 2-15. doi: 10.1016/j.abb.2012.03.008

Kmieć, Z. (2001). Cooperation of Liver Cells in Health and Disease. Berlin: SpringerVerlag. doi: 10.1007/978-3-642-56553-3

Koffler, L., Roshong, S., Park, I. K., Cesen-Cummings, K., Thompson, D. C., Dwyer-Nield, L. D., et al. (2000). Growth inhibition in G(1) and altered expression of cyclin D1 and p27(kip-1) after forced connexin expression in lung and liver carcinoma cells. J. Cell. Biochem. 79, 347-354. doi: 10.1002/10974644(20001201)79:3<347::AID-JCB10>3.0.CO;2-2

Kojima, T., Kokai, Y., Chiba, H., Yamamoto, M., Mochizuki, Y., and Sawada, N. (2001). Cx32 but not Cx26 is associated with tight junctions in primary cultures of rat hepatocytes. Exp. Cell Res. 263, 193-201. doi: 10.1006/excr.2000.5103

Kojima, T., Mitaka, T., Shibata, Y., and Mochizuki, Y. (1995). Induction and regulation of connexin 26 by glucagon in primary cultures of adult rat hepatocytes. J. Cell Sci. 108, 2771-2780.

Kojima, T., Yamamoto, T., Murata, M., Lan, M., Takano, K. I., Go, M., et al. (2003). Role of the p38 MAP-kinase signaling pathway for Cx32 and claudin-1 in the rat liver. Cell Commun. Adhes. 10, 437-443. doi: 10.1080/714040465

Kojima, T. L., Yamamoto, M., Mochizuki, C., Mitaka, T., Sawada, N., and Mochizuki, Y. (1997). Different changes in expression and function of connexin 26 and connexin 32 during DNA synthesis and redifferentiation in primary rat hepatocytes using a DMSO culture system. Hepatology 26, 585-597. doi: 10.1002/hep.510260309

Kren, B. T., Kumar, N. M., Wang, S. Q., Gilula, N. B., and Steer, C. J. (1993). Differential regulation of multiple gap junction transcripts and proteins during rat liver regeneration. J. Cell Biol. 123, 707-718. doi: 10.1083/jcb.123.3.707

Kumar, N. M., and Gilula, N. B. (1986). Cloning and characterization of human and rat liver cDNAs coding for a gap junction protein. J. Cell. Biol. 103, 767-776. doi: $10.1083 /$ jcb.103.3.767

Lee, J. R., and White, T. W. (2009). Connexin-26 mutations in deafness and skin disease. Expert Rev. Mol. Med. 11, e35. doi: 10.1017/S1462399409001276

Li, X., Cao, J., Jin, Q., Xie, C., He, Q., Cao, R., et al. (2008). A proteomic study reveals the diversified distribution of plasma membrane-associated proteins in rat hepatocytes. J. Cell. Biochem. 104, 965-984. doi: 10.1002/jc b. 21680

Locovei, S., Scemes, E., Qiu, F., Spray, D. C., and Dahl, G. (2007). Pannexin1 is part of the pore forming unit of the $\mathrm{P} 2 \mathrm{X}(7)$ receptor death complex. FEBS Lett. 581, 483-488. doi: 10.1016/j.febslet.2006.12.056
Lu, G., Haider, H. K., Porollo, A., and Ashraf, M. (2010). Mitochondriaspecific transgenic overexpression of connexin-43 simulates preconditioninginduced cytoprotection of stem cells. Cardiovasc. Res. 88, 277-286. doi: $10.1093 / \mathrm{cvr} / \mathrm{cvq} 293$

Marx-Stoelting, P., Mahr, J., Knorpp, T., Schreiber, S., Templin, M. F., Ott, T., et al. (2008). Tumor promotion in liver of mice with a conditional Cx26 knockout. Toxicol. Sci. 103, 260-267. doi: 10.1093/toxsci/kfn043

Mhaske, P. V., Levit, N. A., Li, L., Wang, H. Z., Lee, J. R., Shuja, Z., et al. (2013). The human Cx26-D50A and Cx26-A88V mutations causing keratitis-ichthyosisdeafness syndrome display increased hemichannel activity. Am. J. Physiol. Cell Physiol. 304, C1150-C1158. doi: 10.1152/ajpcell.00087.2013

Miyashita, T., Takeda, A., Iwai, M., and Shimazu, T. (1991). Single administration of hepatotoxic chemicals transiently decreases the gap-junction-protein levels of connexin 32 in rat liver. Eur. J. Biochem. 196, 37-42. doi: 10.1111/j.14321033.1991.tb15782.x

Nathanson, M. H., Rios-Velez, L., Burgstahler, A. D., and Mennone, A. (1999). Communication via gap junctions modulates bile secretion in the isolated perfused rat liver. Gastroenterology 116, 1176-1183. doi: 10.1016/S00165085(99)70021-1

Naves, M. M. V., Silveira, E. R., Dagli, M. L. Z., and Moreno, F. S. (2001). Effects of beta-carotene and vitamin A on oval cell proliferation and connexin 43 expression during hepatic differentiation in the rat. J. Nutr. Biochem. 12, 685-692. doi: 10.1016/S0955-2863(01)00187-5

Nelles, E., Butzler, C., Jung, D., Temme, A., Gabriel, H. D., Dahl, U., et al. (1996). Defective propagation of signals generated by sympathetic nerve stimulation in the liver of connexin32-deficient mice. Proc. Natl. Acad. Sci. U.S.A. 93, 9565-9570. doi: 10.1073/pnas.93.18.9565

Neveu, M. J., Babcock, K. L., Hertzberg, E. L., Paul, D. L., Nicholson, B. J., and Pitot, H. C. (1994). Colocalized alterations in connexin 32 and cytochrome P450IIB1/2 by phenobarbital and related liver tumor promoters. Cancer Res. 54, 3145-3152.

Neveu, M. J., Hully, J. R., Babcock, K. L., Vaughan, J., Hertzberg, E. L., Nicholson, B. J., et al. (1995). Proliferation-associated differences in the spatial and temporal expression of gap junction genes in rat liver. Hepatology 22, 202-212. doi: 10.1016/0270-9139(95)90374-7

Nicholson, B., Dermietzel, R., Teplow, D., Traub, O., Willecke, K., and Revel, J. P. (1987). 2 Two homologous protein components of hepatic gap junctions. Nature 329, 732-734. doi: 10.1038/329732a0

Okuda, H., Nishida, K., Higashi, Y., and Nagasawa, K. (2013). NAD(+) influx through connexin hemichannels prevents poly(ADP-ribose) polymerasemediated astrocyte death. Life Sci. 92, 808-814. doi: 10.1016/j.lfs.2013.02.010

Ott, T., Jokwitz, M., Lenhard, D., Romualdi, A., Dombrowski, F., Ittrich, C., et al. (2006). Ablation of gap junctional communication in hepatocytes of transgenic mice does not lead to disrupted cellular homeostasis or increased spontaneous tumourigenesis. Eur. J. Cell Biol. 85, 717-728. doi: 10.1016/j.ejcb.2006.03.004

Paku, S., Nagy, P., Kopper, L., and Thorgeirsson, S. S. (2004). 2-acetylaminofluorene dose-dependent differentiation of rat oval cells into hepatocytes: confocal and electron microscopic studies. Hepatology 39, 1353-1361. doi: 10.1002/hep. 20178

Patel, S. J., Milwid, J. M., King, K. R., Bohr, S., Iracheta-Velle, A., Li, M., et al. (2012). Gap junction inhibition prevents drug-induced liver toxicity and fulminant hepatic failure. Nat. Biotechnol. 30, 179-183. doi: 10.1038/nbt.2089

Paul, D. L. (1986). Molecular cloning of cDNA for rat liver gap junction protein. J. Cell. Biol. 103, 123-134. doi: 10.1083/jcb.103.1.123

Pelegrin, P., and Surprenant, A. (2006). Pannexin-1 mediates large pore formation and interleukin-1beta release by the ATP-gated P2X7 receptor. EMBO J. 25, 5071-5082. doi: 10.1038/sj.emboj.7601378

Pelegrin, P., and Surprenant, A. (2007). Pannexin-1 couples to maitotoxin- and nigericin-induced interleukin-1beta release through a dye uptake-independent pathway. J. Biol. Chem. 282, 2386-2394. doi: 10.1074/jbc.M610351200

Penuela, S., Gehi, R., and Laird, D. W. (2013). The biochemistry and function of pannexin channels. Biochim. Biophys. Acta 1828, 15-22. doi: 10.1016/j.bbamem.2012.01.017

Plotkin, L. I., Manolagas, S. C., and Bellido, T. (2002). Transduction of cell survival signals by connexin-43 hemichannels. J. Biol. Chem. 277, 8648-8657. doi: 10.1074/jbc.M108625200

Qu, Y., Misaghi, S., Newton, K., Gilmour, L. L., Louie, S., Cupp, J. E., et al. (2011). Pannexin-1 is required for ATP release during apoptosis but not for inflammasome activation. J. Immunol. 186, 6553-6561. doi: 10.4049/jimmunol.1100478 
Ramachandran, S., Xie, L. H., John, S. A., Subramaniam, S., and Lal, R. (2007). A novel role for connexin hemichannel in oxidative stress and smoking-induced cell injury. PLoS ONE 2:e712. doi: 10.1371/journal.pone.0000712

Ruch, R. J. (2000). "Role of gap junctions in cellular growth control and neoplasia: Evidence and mechanisms," in Gap Junctions: Molecular Basis of Cell Communiction in Health and Disease, ed C. Peracchia (San Diego, CA: Academic Press), 535-554.

Ruiz-Meana, M., Rodriguez-Sinovas, A., Cabestrero, A., Boengler, K., Heusch, G., and Garcia-Dorado, D. (2008). Mitochondrial connexin43 as a new player in the pathophysiology of myocardial ischaemia-reperfusion injury. Cardiovasc. Res. 77, 325-333. doi: 10.1093/cvr/cvm062

Saez, J. C., Berthoud, V. M., Branes, M. C., Martinez, A. D., and Beyer, E. C. (2003). Plasma membrane channels formed by connexins: their regulation and functions. Physiol. Rev. 83, 1359-1400. doi: 10.1152/physrev.00007

Sandilos, J. K., Chiu, Y. H., Chekeni, F. B., Armstrong, A. J., Walk, S. F., Ravichandran, K. S., et al. (2012). Pannexin 1, an ATP release channel, is activated by caspase cleavage of its pore-associated c-terminal autoinhibitory region. J. Biol. Chem. 287, 11303-11311. doi: 10.1074/jbc.M111.323378

Shiojiri, N., Niwa, T., Sugiyama, Y., and Koike, T. (2006). Preferential expression of connexin 37 and connexin 40 in the endothelium of the portal veins during mouse liver development. Cell Tissue Res. 324, 547-552. doi: 10.1007/s00441006-0165-9

Shoda, T., Mitsumori, K., Onodera, H., Toyoda, K., Uneyama, C., Imazawa, T., et al. (1999). The relationship between decrease in Cx32 and induction of P450 isozymes in the early phase of clofibrate hepatocarcinogenesis in the rat. Arch. Toxicol. 73, 373-3780. doi: 10.1007/s002040050676

Shoda, T., Mitsumori, K., Onodera, H., Toyoda, K., Uneyama, C., Takada, K., et al. (2000). Liver tumor-promoting effect of beta-naphthoflavone, a strong CYP $1 \mathrm{~A} 1 / 2$ inducer, and the relationship between CYP $1 \mathrm{Al} / 2$ induction and Cx32 decrease in its hepatocarcinogenesis in the rat. Toxicol. Pathol. 28, 540-547. doi: $10.1177 / 019262330002800406$

Silverman, W. R., de Rivero Vaccari, J. P., Locovei, S., Qiu, F., Carlsson, S. K., Scemes, E., et al. (2009). The pannexin 1 channel activates the inflammasome in neurons and astrocytes. J. Biol. Chem.. 284, 18143-18151. doi: 10.1074/jbc.M109.004804

Stumpel, F., Ott, T., Willecke, K., and Jungermann, K. (1998). Connexin 32 gap junctions enhance stimulation of glucose output by glucagon and noradrenaline in mouse liver. Hepatology 28, 1616-1620. doi: 10.1002/hep.5102 80622

Sugiyama, Y., and Ohta, H. (1990). Changes in density and distribution of gap junctions after partial hepatectomy: immunohistochemical and morphometric studies. Arch. Histol. Cytol. 53, 71-80. doi: 10.1679/aohc.53.71

Sun, Y., Zhao, X., Yao, Y., Qi, X., Yuan, Y., and Hu, Y. (2012). Connexin 43 interacts with Bax to regulate apoptosis of pancreatic cancer through a gap junctionindependent pathway. Int. J. Oncol. 41, 941-948. doi: 10.3892/ijo.2012.1524

Takeuchi, H., Jin, S., Wang, J., Zhang, G., Kawanokuchi, J., Kuno, R., et al. (2006). Tumor necrosis factor-alpha induces neurotoxicity via glutamate release from hemichannels of activated microglia in an autocrine manner. J. Biol. Chem. 281, 21362-21368. doi: 10.1074/jbc.M600504200

Taub, R. (2004). Liver regeneration: from myth to mechanism. Nat. Rev. Mol. Cell Biol. 5, 836-847. doi: 10.1038/nrm1489

Temme, A., Buchmann, A., Gabriel, H. D., Nelles, E., Schwarz, M., and Willecke, K. (1997). High incidence of spontaneous and chemically induced liver tumors in mice deficient for connexin32. Curr. Biol. 7, 713-716. doi: 10.1016/S09609822(06)00302-2

Temme, A., Ott, T., Dombrowski, F., and Willecke, K. (2000). The extent of synchronous initiation and termination of DNA synthesis in regenerating mouse liver is dependent on connexin32 expressing gap junctions. J. Hepatol. 32, 627-635. doi: 10.1016/S0168-8278(00)80225-1

Temme, A., Stumpel, F., Sohl, G., Rieber, E. P., Jungermann, K., Willecke, K., et al. (2001). Dilated bile canaliculi and attenuated decrease of nerve-dependent bile secretion in connexin32-deficient mouse liver. Pflugers Arch. 442, 961-966. doi: $10.1007 / \mathrm{s} 004240100623$

Theiss, C., Mazur, A., Meller, K., and Mannherz, H. G. (2007). Changes in gap junction organization and decreased coupling during induced apoptosis in lens epithelial and NIH-3T3 cells. Exp. Cell Res. 313, 38-52. doi: 10.1016/j.yexcr.2006.09.029

Thompson, R. J., Zhou, N., and MacVicar, B. A. (2006). Ischemia opens neuronal gap junction hemichannels. Science 312, 924-927. doi: 10.1126/science.1126241
Traub, O., Drüge, P. M., and Willecke, K. (1983). Degradation and resynthesis of gap junction protein in plasma membranes of regenerating liver after partial hepatectomy or cholestasis. Proc. Natl. Acad. Sci. U.S.A. 80, 755-759. doi: $10.1073 /$ pnas.80.3.755

Trudeau, K., Muto, T., and Roy, S. (2012). Downregulation of mitochondrial connexin 43 by high glucose triggers mitochondrial shape change and cytochrome $\mathrm{C}$ release in retinal endothelial cells. Invest. Ophthalmol. Vis. Sci. 53, 6675-6681. doi: 10.1167/iovs.12-9895

Vinken, M. (2012). Gap junctions and non-neoplastic liver disease. J. Hepatol. 57, 655-662. doi: 10.1016/j.jhep.2012.02.036

Vinken, M., Ceelen, L., Vanhaecke, T., and Rogiers, V. (2010a). Inhibition of gap junctional intercellular communication by toxic metals. Chem. Res. Toxicol. 23, 1862-1867. doi: 10.1021/tx100276f

Vinken, M., Vanhaecke, T., and Rogiers, V. (2010b). Emerging roles of connexin hemichannels in gastrointestinal and liver pathophysiology. World J. Gastrointest. Pathophysiol. 15, 115-117. doi: 10.4291/wjgp.v1.i4.115

Vinken, M., Decrock, E., De Vuyst, E., De Bock, M., Vandenbroucke, R. E., De Geest, B. G., et al. (2010c). Connexin32 hemichannels contribute to the apoptotic-to-necrotic transition during Fas-mediated hepatocyte cell death. Cell. Mol. Life Sci. 67, 907-918. doi: 10.1007/s00018-009-0220-2

Vinken, M., Decrock, E., De Vuyst, E., Ponsaerts, R., D’Hondt, C., Bultynck, G., et al. (2011). Connexins: sensors and regulators of cell cycling. Biochim. Biophys. Acta 1815, 13-25. doi: 10.1016/j.bbcan.2010.08.004

Vinken, M., de Kock, J., Oliveira, A. G., Menezes, G. B., Cogliati, B., Zaidan Dagli, M. L., et al. (2012a). Modifications in connexin expression in liver development and cancer. Cell Commun. Adhes. 19, 55-62. doi: 10.3109/15419061.2012.712576

Vinken, M., Decrock, E., Vanhaecke, T., Leybaert, L., and Rogiers, V. (2012b). Connexin43 signaling contributes to spontaneous apoptosis in cultures of primary hepatocytes. Toxicol. Sci. 125, 175-186. doi: 10.1093/toxsci/kfr277

Vinken, M., Doktorova, T., Decrock, E., Leybaert, L., Vanhaecke, T., and Rogiers, V. (2009). Gap junctional intercellular communication as a target for liver toxicity and carcinogenicity. Crit. Rev. Biochem. Mol. Biol. 44, 201-222. doi: 10.1080/10409230903061215

Vinken, M., Henkens, T., de Rop, E., Fraczek, J., Vanhaecke, T., and Rogiers, V. (2008). Biology and pathobiology of gap junctional channels in hepatocytes. Hepatology 47, 1077-1088. doi: 10.1002/hep.22049

Vinken, M., Maes, M., Cavill, R., Valkenborg, D., Ellis, J. K., Decrock, E., et al. (2013). Proteomic and metabolomic responses to connexin 43 silencing in primary hepatocyte cultures. Arch. Toxicol. 87, 883-894. doi: 10.1007/s00204012-0994-0

Vinken, M., Vanhaecke, T., Papeleu, P., Snykers, S., Henkens, T., and Rogiers, V. (2006). Connexins and their channels in cell growth and cell death. Cell Signal. 18, 592-600. doi: 10.1016/j.cellsig.2005.08.012

Wang, N., de Bock, M., Decrock, E., Bol, M., Gadicherla, A., Vinken, M., et al. (2013a). Paracrine signaling through plasma membrane hemichannels. Biochim. Biophys. Acta 1828, 35-50. doi: 10.1016/j.bbamem.2012.07.002

Wang, N., De Bock, M., Decrock, E., Bol, M., Gadicherla, A., Bultynck, G., et al. (2013b). Connexin targeting peptides as inhibitors of voltage- and intracellular $\mathrm{Ca}(2+)$-triggered $\mathrm{Cx} 43$ hemichannel opening. Neuropharmacology 75, 506-516. doi: 10.1016/j.neuropharm.2013.08.021

Wang, N., De Vuyst, E., Ponsaerts, R., Boengler, K., Palacios-Prado, N., Wauman, J., et al. (2013c). Selective inhibition of Cx43 hemichannels by Gap19 and its impact on myocardial ischemia/reperfusion injury. Basic Res. Cardiol. 108, 309. doi: 10.1007/s00395-012-0309-x

Xiao, F., Waldrop, S. L., Khimji, A. K., and Kilic, G. (2012). Pannexin 1 contributes to pathophysiological ATP release in lipoapoptosis induced by saturated free fatty acids in liver cells. Am. J. Physiol. Cell Physiol. 303, C1034-C1044. doi: 10.1152/ajpcell.00175.2012

Yang, J., Ichikawa, A., and Tsuchiya, T. (2003). A novel function of connexin 32: marked enhancement of liver function in a hepatoma cell line. Biochemi. Biophys. Res. Commun. 307, 80-85. doi: 10.1016/S0006-291X(03)01117-3

Yano, T., Hernandez-Blazquez, F. J., Omori, Y., and Yamasaki, H. (2001). Reduction of malignant phenotype of HEPG2 cell is associated with the expression of connexin 26 but not connexin 32. Carcinogenesis 22, 1593-1600. doi: $10.1093 / \mathrm{carcin} / 22.10 .1593$

Yin, X., Gu, S., and Jiang, J. X. (2001). Regulation of lens connexin 45.6 by apoptotic protease, caspase-3. Cell Commun. Adhes. 8, 373-376. doi: $10.3109 / 15419060109080756$ 
Zhang, J. T., and Nicholson, B. J. (1989). Sequence and tissue distribution of a second protein of hepatic gap junctions, Cx26, as deduced from its cDNA. J. Cell. Biol. 109, 3391-3401. doi: 10.1083/jcb.109.6.3391

Zhang, L., Deng, T., Sun, Y., Liu, K., Yang, Y., and Zheng, X. (2008). Role for nitric oxide in permeability of hippocampal neuronal hemichannels during oxygen glucose deprivation. J. Neurosci. Res. 86, 2281-2291. doi: 10.1002/jnr. 21675

Zhang, M. H., and Thorgeirsson, S. S. (1994). Modulation of connexins during differentiation of oval cells into hepatocytes. Exp. Cell Res. 213, 37-42. doi: 10.1006/excr.1994.1170

Conflict of Interest Statement: The authors declare that the research was conducted in the absence of any commercial or financial relationships that could be construed as a potential conflict of interest.
Received: 04 October 2013; paper pending published: 15 November 2013; accepted: 23 December 2013; published online: 10 January 2014.

Citation: Maes M, Decrock E, Cogliati B, Oliveira AG, Marques PE, Dagli MLZ, Menezes GB, Mennecier G, Leybaert L, Vanhaecke T, Rogiers $V$ and Vinken $M$ (2014) Connexin and pannexin (hemi)channels in the liver. Front. Physiol. 4:405. doi: 10.3389/fphys.2013.00405

This article was submitted to Membrane Physiology and Membrane Biophysics, a section of the journal Frontiers in Physiology.

Copyright (c) 2014 Maes, Decrock, Cogliati, Oliveira, Marques, Dagli, Menezes, Mennecier, Leybaert, Vanhaecke, Rogiers and Vinken. This is an open-access article distributed under the terms of the Creative Commons Attribution License (CC BY). The use, distribution or reproduction in other forums is permitted, provided the original author(s) or licensor are credited and that the original publication in this journal is cited, in accordance with accepted academic practice. No use, distribution or reproduction is permitted which does not comply with these terms. 